\title{
From the Woman's Viewpoint: Ethical Dilemmas Confronted by Women as Informal Caregivers of Frail Elders
}

\author{
Terry L. Koenig
}

\begin{abstract}
Women as informal caregivers face complex ethical dilemmas in caring for a frail elder. Through indepth interviews with 13 ethnically diverse caregivers, this qualitative study explored women's ethical decision-making. Focus group interviews of home health staff, key informant caregivers, and interviewees provided guidance for research design, reflection on findings and development of implications. Findings are integrated into an ethical decision-making model that includes types of ethical dilemmas (e.g., protection of life vs. autonomy); feelings that permeate decision making (e.g., fear); processes for addressing ethical dilemmas (e.g., family collaboration); and supportive services. Implications include (a) expansion of services to meet caregivers' ongoing needs, (b) research that acknowledges multiple decision-making components, and (c) the use of caregiving vignettes in the classroom.
\end{abstract}

$\mathbf{W}$ omen as informal caregivers face a myriad of ongoing and complex ethical dilemmas in caring for a frail elder (Bopp \& Coleson, 1996; Glover, 1994; Jecker, 1991). An ethical dilemma can be defined as a conflict in which the caregiver must make a choice "between two or more relevant, but contradictory ethical directives, or when every alternative results in an undesirable outcome for one or more persons" (Loewenberg, Dolgoff, \& Harrington, 2000, p. 9). For example, one caregiver, providing care for her husband, was torn between whether or not to put a lock on their bedroom door. Her husband had poor judgment and difficulties walking due to a stroke and was trying to climb their steps to his carpentry shop late at night. She feared for his safety and thought he might harm himself climbing these steps. She was also getting little sleep, and this added to the stress of caring for her husband. The caregiver felt tension between (a) wanting to make sure her husband was safe and needing to take care of her own health needs for restful sleep and reduced stress and (b) supporting her husband's right to move freely about the house. The frail elder's safety needs conflicted with the caregiver's self-care needs. This example represents only one kind of ethical dilemma or tension between competing values and needs that informal caregivers confront in an effort to provide daily elder care.

Gerontological writers describe the importance of ongoing discussions among elders, informal caregivers, and significant others about ethical dilemmas, competing values, and decision making on such topics as health care treatment and home-care options (Bopp \& Coleson, 1996; Jecker, 1991; Spano \& Koenig, 2003). However, rarely have research efforts examined the way informal caregivers themselves define and deal with these dilemmas. This article reports on a qualitative study that explored female 
caregivers' perspectives about ethical dilemmas. Women face ethical dilemmas almost daily in caring for a frail elder. Finding out what they struggle with and the strategies they use to deal with or overcome these dilemmas can help researchers, policy makers, practitioners, and educators provide support and assistance to caregivers and frail elders.

\section{Literature Review}

\section{Aging and Ethics}

Few empirically based studies explore ethical dilemmas and processes for dealing with them from the informal caregiver's viewpoint (Hasselkus, 1991; Pyke \& Bengston, 1996). Current trends in the caregiving literature emphasize conceptual writings that explore the ethical dilemmas and decision-making processes of the professional caregiver. Ethical dilemmas for professionals are typically described within acute care and institutional settings using bioethics models. For example, gerontological writers address professional caregivers' ethical dilemmas in dealing with end-oflife treatment (e.g., whether or not to use a feeding tube; Beauchamp \& Childress, 1994; Cole \& Holstein, 1996) and the ethical decision-making processes leading up to or occurring within institutional settings (e.g., whether or not to place a patient in a structured facility; Jecker, 1991; McCullough, Wilson, Rhymes, \& Teasdale, 1999).

These conceptual writings on ethics and aging indicate that bioethics decision-making models address a type of decision making (e.g., time-limited decisions within a controlled environment such as a hospital, an emphasis on one decision maker such as the patient or surrogate, and the dominance of professionals in decision making) that is not readily transferable to long-term, home-based settings. Several factors account for this including less control of home-based treatment by health care providers, the larger role of family and others in the decision-making process, and psychosocial factors that lead to increased complexity in health care treatment (e.g., minimal financial resources).

\section{Social Work Ethics}

Social work writings on professional ethics describe two major philosophical perspectives involved in ethical decision-making: (a) ethical absolutism and (b) ethical relativism (Loewenberg, Dolgoff, \& Harrington, 2000; Reamer, 1982, 1998; Rhodes, 1985). Ethical absolutism stresses the importance of fixed ethical principles or rules (e.g., confidentiality, Congress, 1999, and informed consent, Reamer, 1987) in decision-making processes. Ethical relativism emphasizes decision making based on (a) social, historical, cultural, and other factors related to context and (b) possible consequences. Social work practitioners, many of whom are women, confront unique practice situations on a daily basis. Social workers are also understood to predominantly use ethical relativism in making decisions in professional life. Furthermore, moral- and cognitive-development research describes women as taking an ethical relativist position in reference to ethical dilemmas (Gilligan, 1982; Rhodes, 1986; Skoe \& von der Lippe, 1998). Ethical relativism, central to social workers' ethical decision-making processes as well as to the clients they work with, provides a framework for understanding how female caregivers deal with ethical dilemmas within unique caregiving contexts.

\section{Research Questions}

Three overarching research questions were proposed to explore the ethical dilemmas and processes for dealing with these dilemmas from the caregiver's viewpoint.

1. What are the ethical dilemmas that female caregivers face in caring for a frail elder in the home setting?

2. What are the processes female caregivers describe in dealing with or resolving ethical dilemmas?

3. What recommendations do female caregivers have for enhancing services to help address ethical dilemmas?

\section{Method}

The researcher, a medical social worker for 11 years, worked extensively with caregivers and frail elders to help them maintain independent functioning while adjusting to changing health needs. This work experience deepened the researcher's understanding of women's decision-making capabilities and influenced her motivation to conduct this qualitative study. This study used naturalistic inquiry, which supports the use of a qualitative design, to explore female caregivers' experiences of ethical dilemmas.

Because minimal systematic research has been conducted on female caregivers' experiences of ethical dilemmas, a qualitative design that emphasizes the emergence of ideas, major themes, conclusions, and grounded theory that emerges from an analysis of the data lent itself well to this exploration. The use of semistructured interviews with open-ended questions enabled women to depict detailed stories of decision-making processes in addressing ethical dilemmas. These in-depth interviews provided caregivers the opportunity to describe a broad range of factors that impact their ethical decision-making (e.g., the caregiver's home setting and interactions with significant others).

Two key concepts are delineated for the purpose of this study. A frail elder is defined as any person age 65 or older needing assistance from a caregiver with one or more activities of daily living such as bathing, ambulation, money management, and household chores. An informal, primary caregiver provides the major source of care in the home for a frail elder. An informal caregiver is distinguished from a professional health care provider (Barer \& Johnson, 1990; Montgomery, 1996). Furthermore, because so little research has been conducted on ethical dilemmas from the caregiver's viewpoint and because the majority of informal caregivers are women (over 73\%), this researcher chose to interview only women (National Alliance for Caregiving \& American Association of Retired Persons, 1997). 
Caregivers were recruited from clients of a local homehealth agency and its parent hospital. These caregivers resided in Leavenworth, Kansas, and the surrounding rural areas. Fourteen caregivers were selected using purposive sampling (based on variance in the following selection criteria) in order to obtain a broad range of perspectives concerning the research questions. Selection criteria, developed from studies on factors that contribute to caregiver burden and stress (Pearlin, Mullan, Semple, \& Skaff, 1990; Toseland, Labrecque, Goebel, \& Whitney, 1992), included (a) cognitive status of the frail elder (severe to no cognitive impairment); (b) perceived financial strain (severe to no strain); (c) the frail elder's resistance to the caregiver's help (severe to no resistance); (d) caregiver's employment (yes or no); and (e) the length of time the caregiver had provided care (from 2 weeks to over 10 years).

A consultant panel, organized by the researcher, provided (a) guidance throughout the design process, for example, identification of additional selection criteria to include child-care status (yes or no) and the status of the caregivers' health (excellent to poor) and (b) pilot testing of the interview guide. The consultant panel consisted of home-health agency staff (four registered nurses, one bachelors' level social worker, and a physical therapist) and two caregivers from the agency-sponsored caregivers' support group.

After the selection criteria were finalized, the home-health agency obtained written permission from applicable caregivers to be contacted by the researcher for possible participation in this study. All 14 women agreed to participate in the study; 1 spousal caregiver became ineligible because of the death of her husband. An introductory letter was sent 1 week before the scheduled interview explaining the research study's purpose and procedures. Participants were encouraged to think about ethical dilemmas or hard choices in such areas as social support from family and friends, the frail elder's resistance to the caregiver's help, the effects of childcare, and the caregiver's health. Questions asked in each area included the following: Describe a hard choice you have faced as a caregiver (in this area). How did you deal with this hard choice? Did you resolve it? Please explain.

The researcher recorded field notes of observations immediately after she completed each interview. All interviews and field notes were audiotaped by the researcher. Eleven interviews occurred in the caregiver's homes, and two occurred at a place chosen by the caregiver. Individual interviews with caregivers spanned 1.5-3 hours each, with follow-up interviews lasting 15-60 minutes.

The constant comparative method of qualitative data analysis as described by Lincoln and Guba (1985) was used to analyze the interviews and observations. The researcher analyzed the data by using an iterative process of moving back and forth between the raw data and tentative codes until final coding categories were developed. Specified themes and a working model of caregivers' ethical decisionmaking processes emerged from the data analysis.

Several strategies were used to establish trustworthiness in the study's findings (e.g., the consultant panel, member checking, and focus groups). Consultant panel members gave feedback on introductory themes and case vignettes of ethical dilemmas as a way of refining and confirming findings. The researcher also conducted member checks as to the understanding and accuracy of findings with research participants. For example, as each caregiving story was recounted, the researcher paraphrased the caregiver's responses to determine if a situation presented a "hard choice" (ethical dilemma) or to clarify how a caregiver had resolved a particular dilemma. By paraphrasing caregivers' responses, the researcher was able to check out the accuracy of her understanding of the caregivers' responses, thereby further confirming findings. Finally, in focus groups, members of the consultant panel and interviewees confirmed a preliminary report of major findings and tentative conclusions. Through the use of these strategies, interview participants were able to assert their perspectives as a way to refine and add credibility to the findings.

\section{Findings}

\section{Demographic Characteristics}

Demographic characteristics were collected on caregivers including age, marital status, relationship to the frail elder, ethnicity, level of education, employment status, and child or grandchild care status. Caregivers ranged in age from 49 to 85 years old and included 8 spouses, 2 daughters, 1 significant other, 1 daughter-in-law, and 1 mother. All but 2 caregivers described multiethnic backgrounds. Two were of full European ethnicity, 7 of mixed European ethnicity, 2 of mixed European and Native American ethnicity, 1 of mixed Native American and African American ethnicity, and 1 of mixed European, African American, and Native American ethnicity.

Caregivers reported diverse educational backgrounds. One completed junior high, 3 finished part of high school, 4 finished high school, 3 completed high school and some college courses, 1 completed an undergraduate college degree, and 1 completed a master's degree. Five caregivers were employed outside the home. Two caregivers provided 


\section{Mary faced an ongoing ethical dilemma.... For about 90 minutes, Grace was left \\ alone until paid help could come to the home to provide supervision.}

care for children who lived in the home; 2 caregivers provided periodic care for grandchildren.

Analysis indicated that no distinct subgroups of the research participants—such as adult daughters and wives, ethnically diverse participants, and variances in education or employment outside the home-clearly distinguished the kinds of ethical dilemmas, processes for dealing with ethical dilemmas, or informal supports and services needed to best deal with ethical dilemmas.

However, four overarching themes emerged from interviews with caregivers. These themes included (a) types of ethical dilemmas, (b) decision-making processes for dealing with these dilemmas, (c) feelings that permeated the decision-making process, and (d) informal supports and formal services needed to best deal with these dilemmas. These key components of ethical decision-making emerged to help form a tentative working model that illustrates ethical decision-making for female caregivers. What follows is a discussion of each theme, highlighted with caregivers' examples and quotes. (Each caregiver is given a fictitious name.) Finally, 1 caregiver's ethical decision-making vignette is used to demonstrate the working model.

\section{Types of Ethical Dilemmas}

Caregivers described various types of ethical dilemmas involving conflicting ethical principles (e.g., quality of life vs. protection of life; social justice vs. autonomy). The following discussion highlights the ethical dilemma of quality of life versus protection of life. Seven caregivers struggled to balance their need for employment or time with friends and family (quality of life) with the frail elder's safety and supervision needs (protection of life).

One caregiver, Rita, was torn over spending time with family and friends versus staying by her partner's side in the hospital. Rita was concerned for her partner's safety (protection of life) and made the decision to stay with him. Rita stated, "I wouldn't leave the hospital and it was a choice, like shall I go and be with my family ... or shall I stay with him because something could happen to him."

Another caregiver, Mackenzie, described the struggle she faced about employment. Mackenzie stated,

I took one of those federal medical leaves for families and I haven't went back yet. And then I took my mom [the frail elder] to the doctor ... and she tells me that I still can't go back. She doesn't know if I'll ever be able to leave mom, so I got to make a decision on that one.
Finally, because of the frail elder's increased health problems, 2 spousal caregivers, Cora and Sarah, struggled with whether or not they could safely provide for the frail elder. Both contemplated nursing-home placement. Cora stated, "I did not want that [nursing-home placement]." Sarah remarked, "Probably the hardest choice was what was I going to do? How was I going to do this? The focus was a nursing home for him." Both Cora and Sarah decided against nursing-home placement in favor of home care (e.g., improved quality of life) for the frail elder.

\section{Feelings That Permeate the Decision-Making Process}

Anger, guilt, sadness, and fear are just a few of the feelings that caregivers described as part of dealing with or resolving ethical dilemmas. Often, feelings arose before, during, and after the ethical decision-making process. The occurrence of feelings along many points of the decision-making process reflected the ongoing nature of ethical dilemmas that are initially struggled with and often continue to be dealt with over time.

For example, 6 caregivers described fear in dealing with an ethical dilemma. One caregiver, Mackenzie, faced her fears in dealing with a series of ethical dilemmas about whether or not to provide care for her mother and whether or not to be her durable power of attorney. Mackenzie described her initial reaction to her new role of being the main person responsible for her mother's care and well-being. She stated, "I was kind of scared in the beginning. I didn't think I was capable of taking care of her at the time, but it worked out." Mackenzie successfully overcame her fears as a way to deal with these ethical dilemmas.

Fear also contributed to Bea's refusal to use a lightweight wheelchair she bought for her husband, the frail elder. Bea remarked, "Had to go get the wheelchair and I didn't know anything about wheelchairs." She was afraid of harming her husband and stated, "I'm waiting until a relative that is a nurse comes by and I'm going to have a course on wheelchairs." By waiting, Bea managed her fears and simultaneously protected the frail elder. In conclusion, feelings such as fear often must be overcome or managed in the process of dealing with ethical dilemmas.

\section{Decision-Making Processes for Dealing With Ethical Dilemmas}

The researcher asked caregivers, "How did you deal with this hard choice (ethical dilemma)?" This question allowed caregivers to describe in their own words various processes 
for working through dilemmas, including the use of structure and organization, collaboration, spirituality, direct communication (such as assertiveness), self-reflection, consideration of different consequences, and avoidance of conflict with others. For the purposes of this article, collaboration and spirituality are highlighted as processes for working through ethical dilemmas.

Collaboration. Seven caregivers described collaboration with adult children, siblings, or the frail elder as a way to deal with an ethical dilemma. One spousal caregiver, Sophia, had recently recovered from a stroke. Through discussions with her spouse and adult children, she dealt with the ethical dilemma of whether or not to move out of her home of 50 years. Her adult children described her mild stroke as a "wake-up call" for making other housing arrangements. Through tears, Sophia stated that she and her husband "needed to make some plans on what to do" and that they had finally made the decision to move out of their home and into supportive housing.

Another caregiver, Sarah, collaborated with her husband, the frail elder in dealing with an ethical dilemma involving his alcohol abuse. Her husband was having problems "with his stools and seemed not to have control." Sarah remarked,

We ... traced it back, after I talked with him, because he's so embarrassed when this happens, that I have to clean up after him.... We decided together, without a whole lot of arguing. And so he just doesn't do that [drink alcohol] much any more and we haven't had any accidents lately.

Sarah collaborated with her husband, and they developed a plan together to better manage his behavior. As illustrated in these examples, collaboration helped caregivers address ethical dilemmas.

Spirituality. Spirituality, defined as the caregivers' search for meaning and purpose in providing care for the frail elder that involves both religious and nonreligious or noninstitutional expression, was used by all caregivers to deal with or resolve ethical dilemmas. For example, Rita referred to the importance of her spiritual beliefs in deciding to care for the care receiver. She stated, "I don't think there are miracles ... but I think if you feel you want to help yourself, you can." A belief in God and positive thinking helped Rita deal with the ethical dilemma of providing home care.

Vera, who wore a Jesus lapel pin during the interview, described her dilemma about whether or not to take her daughter, the frail elder, out of a nursing home and care for her at home. Because of the caregiver's own health care issues (injured hip with difficulty walking), family members discouraged Vera from making the decision to provide home care. Vera remarked, "You could call me a religious fanatic ...'cause I deal with [sic], I read a lot of scriptures." These religious practices helped Vera manage conflict with her family and make the decision to provide home care for her daughter. In conclusion, caregivers defined collaboration with others and spirituality as decision-making processes that they used to deal with ethical dilemmas.

\section{Informal Supports and Formal Services}

Caregivers were specifically asked about services that they used or did not have that could best help them in dealing with dilemmas. All caregivers described both benefiting from and lacking formal services (e.g., rehabilitation services) or informal supports (e.g., social support from family and friends) as a way to deal with or help resolve ethical dilemmas. This section highlights informal caregivers' use of paid caregiving as a formal service to help deal with ethical dilemmas.

Eight caregivers used paid caregiving for a variety of reasons such as medication management, housekeeping, rehabilitation therapies, bathing, counseling, or supervision for the frail elder. For 4 women, the ethical dilemma about whether or not to work was at least partially dealt with or resolved by hiring a paid caregiver. For example, Mary hired a "stranger" or paid caregiver from a community-based home-health agency to supervise the frail elder while she worked in the evenings. Although not excited about the intrusiveness of this arrangement into Mary's privacy, Mary needed the paid help. Mary stated that the paid caregiver has "got to learn our routine ... and she's got to feel real comfortable with the [frail elder] ...please that little old lady sitting in that chair."

Even though many caregivers described having access to paid help, just as often, they described not having paid help to deal with ethical dilemmas. For example, Tessa described one of her major ethical dilemmas as a caregiver. "Just going to work every day is the biggest thing. Because I don't have anybody here with him.... And some days I know that he doesn't feel good enough that I should leave him by himself." Regardless of her husband's need for supervision, Tessa had to maintain employment. In conclusion, caregivers described the use of formal services in managing dilemmas.

\section{An Example of Ethical Decision Making: Mary's Vignette}

The following vignette illustrates the above described key components of ethical decision making. Mary was a 52year-old, widowed woman who cared for her mother-inlaw, Grace. Having lost her husband and parents in the last few years, Mary stated that living together with her motherin-law provided companionship for both of them. Grace had Parkinson's disease with dementia and weighed only 75 lb $(34 \mathrm{~kg})$. She required constant supervision, assistance with transfers, food preparation, and assistance with bathing, dressing, and medication management.

Mary faced an ongoing ethical dilemma in leaving her mother-in-law alone (protection of life) while she went to work (quality of life). For about 90 minutes, Grace was left alone until paid help could come to the home to provide 
supervision. Mary engaged in a decision-making process by relying on her faith and discussing these concerns with her mother-in-law, the frail elder. She stated,

The hardest choice is me walking out the door and just hoping that the next person comes in and she's still there. It's a crapshoot. We don't know how long we live. It's blind faith that the next person will find her alive and healthy. That's the bottom line. That's the hardest choice-is leaving her every morning.

Mary and her mother-in-law discussed this work arrangement and agreed that they could not pay for more home care. This was an ethical dilemma involving finances: Mary had to maintain employment to provide a decent quality of life for both of them. However, this did not alleviate Mary's fears. She stated, "I'm scared that she's going to die and nobody's going to be there with her in that hour and a half." Mary dealt with her strong feelings of fear by calling Grace as soon as she got to work each day. She stated that Grace "better pick up that damn phone and push talk." Mary's vignette illustrates a type of ethical dilemma (quality of life vs. protection of life), feelings that permeate the ethical decision-making process (such as fear), decisionmaking processes (collaboration and the use of spirituality), and services needed or used (such as paid caregiving).

\section{Implications}

\section{Policy and Practice}

Like Mary in the previous vignette, 6 caregivers in this study struggled to obtain constant supervision for the frail elder. When possible, caregivers relied on family and friends or obtained paid help to supervise the frail elder. However, all of these caregivers were unsuccessful at some point in obtaining needed supervision. Without affordable and reliable help to supervise the frail elder, caregivers experienced ethical dilemmas involving their quality of life (e.g., employment to provide adequate income, time with family and friends, or breaks from caregiving) versus protection of life for the frail elder.

Ethical dilemmas brought on by a sustained lack of services for caregivers are unlikely to recede. Policy makers and practitioners continue to describe a lack of services to meet the long-term needs of the frail elder and hence the caregiver (Purk \& Richardson, 1994). Furthermore, because homebased services supported by Medicare and Medicaid are centered on the acute needs of the frail elder, the caregivers' needs (e.g., for supervision) are often ignored, or limits are placed on resources for using paid help in chronic, long-term caregiving situations. Another step in Medicare and Medicaid policy changes would be to expand the length of time over which a caregiver and frail elder could receive formal social services. These changes would take into account the chronic nature of many older persons' health care needs as well as the caregivers' ongoing needs for support (Browne, 1998).

\section{Research}

The working model presented in this study can help researchers explore specific components of ethical decisionmaking as understood within a larger caregiving context. Current caregiving studies focus on a small collection of caregiving components, such as the physical demands of caregiving or the caregiver's employment, as each adversely impacts ethical dilemmas and decision-making processes (Bedini \& Guinan, 1996; Pratt, Schmall, \& Wright, 1987). In contrast, the proposed ethical decision-making model incorporates caregivers' distinctive viewpoints and narratives about ethical dilemmas and provides a more holistic picture of the complex nature of caregivers' ethical decision making in such areas as the caregiver's feelings of guilt or fear and needed services. In order to find practical solutions that are useful to caregivers, researchers must take into account the interactions of many ethical decision-making components. Without an overarching model of the way women address ethical dilemmas, caregiving components are studied in a vacuum, cut off from the very context of daily ethical decision-making processes experienced in caregiver's lives.

\section{Education}

The proposed model can be used in classroom and agency settings to demonstrate the complex nature of ethical decision-making that permeates the caregiving experience. Caregiving narratives or vignettes of ethical dilemmas and decision-making processes further illustrate the mutual interactions and flow among various components of the ethical decision-making model. These vignettes provide a way for students, educators, and agency staff to closely examine the nature of caregiving and can further stimulate possible strategies for supporting caregivers.

In conclusion, female caregivers face multiple, complex, and often daily ethical dilemmas as they provide home care for frail elders. The research literature has largely ignored women's distinctive voices of the ethical dimensions of caregiving. This study proposes an ethical decision-making model that emerged from women's unique viewpoints about the ways in which they process and deal with ethical dilemmas as caregivers. Paying attention to the complex decision-making processes expressed through women's caregiving narratives provides ample opportunities for strengthening social work's research, practice, policy, and education efforts with caregivers.

\section{References}

Barer, B. M., \& Johnson, C. J. (1990). A critique of caregiving literature. The Gerontologist, 30, 26-29.

Beauchamp, T. L., \& Childress, J. F. (1994). Principles of biomedical ethics (4th ed.). New York: Oxford University Press.

Bendini, L. A., \& Guinan, D. M. (1996). "If I could just be selfish...": Caregivers' perceptions of their entitlement to leisure. Leisure Sciences, 18, 227-239.

Bopp, J., Jr., \& Coleson, R. E. (1996). A critique of family members as proxy decision makers without legal limits. Issues in Law and Medicine, 12, 244. 
Browne, C. (1998). Women, feminism, and aging. New York: Springer.

Cole, T. R., \& Holstein, M. (1996). Ethics and aging. In R. H. Binstock \& L. K. George (Eds.), Handbook of aging and the social sciences (pp. 480-497). San Diego, CA: Academic Press.

Congress, E. P. (1999). The new confidentiality for the 21 st century in a managed care environment. Social Work, 44, 253-262.

Gilligan, C. (1982). In a different voice: Psychological theory and women's development. Cambridge, MA: Harvard University Press.

Glover, J. J. (1994). Symposium: Trends in health care decision making: Should families make health care decisions? Maryland Law Review, 53, 1158.

Hasselkus, B. R. (1991). Ethical dilemmas in family caregiving for the elderly: Implications for occupational therapy. The American Journal of Occupational Therapy, 45, 206-212.

Jecker, N. S. (1991). The role of intimate others in medical decision making. In N. S. Jecker (Ed.), Aging and ethics: Philosophical problems in gerontology (pp. 199-216). Clifton, NJ: Humana Press.

Lincoln, Y. S., \& Guba, E. G. (1985). Naturalistic inquiry. Beverly Hills, CA: Sage.

Loewenberg, F., Dolgoff, R., \& Harrington, D. (2000). Ethical decisions for social work practice (6th ed.). Itasca, IL: Peacock.

McCullough, L. B., Wilson, N. L., Rhymes, J. A., \& Teasdale, T. A. (1999). Ethical issues in long term care. In T. F. Johnson (Ed.), Handbook on ethical issues in aging (pp. 305-325). Westport, CT: Greenwood Press.

Montgomery, R. J.V. (1996). The influence of social context on the caregiving experience. In Z. S. Khachaturian \& T. S. Radebaugh (Eds.), Alzheimer's disease: Cause(s), diagnosis, treatment and care (pp. 311-319). Boca Raton: CRC Press.

National Alliance for Caregiving, \& American Association of Retired Persons. (1997). Family caregiving in the United States: Findings from a national survey. Bethesda, MD, and Washington, DC: Author.

Pearlin, L. I., Mullan, J. T., Semple, S. J., \& Skaff. M. M. (1990). Caregiving and the stress process: An overview of concepts and their measures. The Gerontologist, 30, 583-594.

Pratt, C. C., Schmall V., \& Wright, S. (1987). Ethical concerns of family caregivers to dementia patients. The Gerontologist, 27, 632-638.
Purk, J. K., \& Richardson, R. A. (1994). Older adult stroke patients and their spousal caregivers. Families in Society, 75, 608-615.

Pyke, K. D., \& Bengtson, V. L. (1996). Caring more or less: Individualistic and collectivist systems of family eldercare. Journal of Marriage and Family, 58, 379-392.

Reamer, F. G. (1982). Ethical dilemmas in social services. New York: Columbia University Press.

Reamer, F. G. (1987). Informed consent in social work. Social Work, 32, 425-429.

Reamer, F. G. (1998). The evolution of social work ethics. Social Work, 43, 488-500.

Rhodes, M. L. (1985). Gilligan's theory of moral development as applied to social work. Social Work, 30, 101-105.

Rhodes, M. L. (1986). Ethical dilemmas in social work practice. Boston: Rutledge and Paul Kegan.

Skoe, E. E. A., \& von der Lippe, A. L. (Eds.). (1998). Personality development in adolescence: $A$ cross national and life span perspective. New York: Routledge.

Spano, R. N., \& Koenig, T. L. (2003). Moral dialogue: An interactional approach to ethical decision making. Social Thought, 22, 94-102.

Toseland, R. W., Labrecque, M. S., Goebel, S. T., \& Whitney, M. H. (1992). An evaluation of a group program for spouses of frail elderly veterans. The Gerontologist, 32, 382-390.

Terry L. Koenig, PhD, is assistant professor, School of Social Work, 685 Baldy Hall, University at Buffalo, State University of New York Buffalo, NY 14260-1050. Prior to entering academia, Professor Koenig worked as a medical social worker with aging adults and their families and significant others. Correspondence regarding this article may be addressed to Terry L. Koenig at tkoenig@buffalo.edu.

Manuscript received: September 30, 2002

Revised: August 30, 2003

Accepted: October 31, 2003 